\title{
Clientelismo político en la gestión pública: Características y consecuencias como forma de dominación política
}

\author{
Political patronage in municipal public management: Characteristics \\ and consequences as a form of political domination
}

\section{Antonio Yesid Pedroza Estrada* y Robert Romero Ramírez ${ }^{* *}$}

\section{RESUMEN}

La investigación tuvo por objetivo analizar el clientelismo político en la gestión pública municipal considerando sus características y consecuencias como forma de dominación política en el municipio Valledupar departamento del Cesar, Colombia durante el periodo 2011 a 2015. El estudio siguió una metodología cualitativa, de tipo documental hermenéutica interpretativa con un diseño bibliográfico y sustentado en autores como Machado (2007), González (2007), Graziano (1975), Kitschelt, (2007), entre otros.Como instrumento de recolección de datos, se utilizó la ficha y la técnica fue el subrayado de los documentos revisados, tales como programas de gobierno, memoria y cuentas, Leyes de la República de Colombia, reglamentos y sentencias sobre el objeto de estudio. Luego de haber analizado los hallazgos, partiendo de los aportes de los teóricos más la interpretación del investigador, se deriva que las características más importantes del clientelismo son la colonización del aparato estatal, asignación de puestos burocráticos y flujo de dineros estatales. Como consecuencias, tiene que las instituciones participantes en relaciones de clientelismo, terminan dependiendo del poder político para recibir privilegios o favores generando en desigualdad de oportunidades con aquellas fuera de dicha relación. Además, los recursos financieros para obtener los favores de la clientela, proceden por lo general, del erario público cuando éstos deberían ser empleados en las prioridades del país. En conclusión, el clientelismo ha permeado el sistema político colombiano a nivel municipal, estableciendo relaciones jerárquicas desiguales, brindando la promoción de votos a cambio de protección, dispensa de favores o asignación de recursos públicos. Esta situación, desvirtúa el empoderamiento de la ciudadanía en cuanto a participar de forma autónoma en los procesos electorales.

\footnotetext{
*Abogado, Doctor en Ciencias Políticas. Valledupar, Colombia. Correo electrónico: yesithpedroza@hotmail.com

${ }^{* *}$ Abogado, Doctor en Ciencias Políticas. Valledupar. Colombia. Correo electrónico: rrrjuris@ @otmail.com 
Palabras clave: Clientelismo político, gestión pública, relaciones de poder, desigualdad.

RECIBIDO: Marzo 2018 ACEPTADO: Abril 2018

\begin{abstract}
The objective of the research was to analyze political patronage in municipal public management considering its characteristics and consequences as a form of political domination in the municipality of Valledupar department of Cesar, Colombia during the period 2011 to 2015. The study was conducted following a qualitative methodology, interpretative hermeneutic type with a bibliographic design and was based on authors such as Machado (2007), González (2007), Graziano (1975), Kitschelt, (2007), among others. As an instrument for data collection was used the file and the technique was the underlining of the documents reviewed, such as government programs, memory and accounts, laws of the Republic of Colombia, regulations and judgments on the object of study. After having analyzed the findings, starting from the contributions of the theorists plus the interpretation of the researcher, it is derived that the most important characteristics of political patronage are the colonization of the state apparatus, assignment of bureaucratic posts and flow of state monies. As consequences, the institutions that participate in patronage relationship end up depending on the political power to receive privileges or favors, generating inequality of opportunities with those outside of this relationship. In addition, the financial resources to obtain the favors of the clientele usually come from the public treasury when these should be used in the priorities of the country. In conclusion, the patronage has permeated the Colombian political system at the municipal level, establishing unequal hierarchical relations, providing the promotion of votes in exchange for protection, dispensation of favors or allocation of public resources. This situation distorts the empowerment of citizens in terms of participating autonomously in electoral processes.
\end{abstract}

Key words: political patronage, public management, power relations, inequality.

\title{
Introducción.
}

El clientelismo en Latinoamérica, ha sido instaurado como una manera de asegurar la articulación entre los sectores populares y la oligarquía, a través de la clase media. Como plantea Valenzuela (1977) desde finales de los años setenta, el funcionamiento de las relaciones clientelares basadas en el predominio de intermediarios políticos.

Desde la concepción democrática, si aplican las normas electorales, legalmente 
Clientelismo político en la gestión pública: Características y consecuencias como forma de dominación política

evitarían no sólo intereses individuales, sino también colectivos; así como el despilfarro de los recursos del Estado; los conflictos políticos entre los partidos, representantes y electores, del mismo modo la compra-venta de votos, entre otras situaciones incidentes en desvirtuar una sana competencia política. Es importante resaltar, los países al poner en práctica el estado social de derecho, una verdadera democracia y un sistema político transparente, funcionan adecuadamente a pesar de poseer un sistema electoral con imperfecciones, además mantienen una política social en equidad y una verdadera justicia social.

En opinión de Audelo (2004), el clientelismo político es una herramienta al servicio de múltiples intereses, el cual proviene de una relación de intercambio voluntario de algún un tipo de capital económico por uno político, dándose entre funcionarios públicos y ciudadanos necesitan algún servicio o recurso, beneficiándose ambas partes. En este sentido, plantear como un arreglo social, representado por las redes clientelares receptoras de beneficios al recibir tanto bienes como servicios a cambio de lealtades políticas, con el correspondiente respaldo, apoyo y votos.

En algunos casos, suelen asociar las prácticas del clientelismo con acciones antidemocráticas. En cualquier caso, en aquellos lugares donde haya algún poder por administrar es posible encontrar al clientelismo, quien posee el poder puede, en un momento dado, favorecer a una determinada persona de su interés, con el fin de compensarle la fidelidad, lealtad, y cooperación prestada de alguna manera. Uno de los problemas de esta situación, además de la opacidad que la caracteriza, es la incapacidad o pocos méritos de la persona beneficiada.

A nivel mundial, específicamente en España, según Corzo (2006) las relaciones de clientela han sido utilizadas de forma distinta en cada periodo histórico. En unos casos, han estado al servicio del poder central para estabilizar los procesos de cambio, en otros suceden empleado para aglutinar las facciones de un partido y fortalecerlo. Igualmente, ha sido un instrumento de persuasión para influir en las conductas de los ciudadanos y de los representantes de éstos, cuando ambos han 
estado sometidos a un poder económico del cual depende su subsistencia.

Por otro lado, para Kitschelt, (2007) en el interior de los partidos desarrollan más nítidamente las relaciones clientelares y son además aceptadas como parte del juego político, donde quien posee mayor posibilidad de acceso a la distribución de bienes y servicios, podrá entregar una oferta a sus militantes, adherentes o simpatizantes incondicionales, quienes conservaran ésta condición de incondicionalidad mientras mantenga la seguridad laboral o económica para el cliente del partido.

Cabe acotar, según este autor, el clientelismo es desarrollado en los partidos políticos existentes en las sociedades demócratas actuales, intercambiando votos por soluciones sociales, apoyo político por cargos públicos entre otros. En este orden, la distribución de recursos está sujeta a la agenda política, la elaboración de los planes respectivos, a las decisiones de quienes ostentan el poder; siendo el ciudadano a través sus necesidades, exigencias y participación, quien determina la primacía de los programas públicos.

En Colombia en la década del 50, de acuerdo con González (2007) los partidos tradicionales firmaron un pacto para alternarse en el ejercicio del gobierno, repartiéndose el aparato estatal, excluyendo a cualquier otro actor político tanto de la contienda electoral como de la posibilidad de conducir los destinos del país. En esas circunstancias, la interacción gobernantes-gobernados en períodos no electorales, tenía lugar a través de la movilización, la protesta reivindicativa y, principalmente, con el uso de canales informales articulados por medio de redes de clientela controladas férreamente por la dirigencia política.

Dentro de este marco, en el municipio Valledupar del Departamento del Cesar, Colombia, el régimen electoral se encuentra inmerso en un sistema político cuya función está sustentada en establecer quiénes pueden aspirar a ejercer el poder como autoridad municipal o regional y los partidos donde militan; en consecuencia, los representantes de las corporaciones administrativas de los diferentes partidos políticos, deben regir por las normas reglamentadas en la Constitución Política de 
Clientelismo político en la gestión pública: Características y consecuencias como forma de dominación política

Colombia (Asamblea Nacional Constituyente, 1991), en la cual invita a la transparencia, honestidad, representatividad, menos personalismo y una verdadera democracia.

No obstante, a través de indagaciones empíricas realizadas por los investigadores en el municipio Valledupar, por ser la capital del departamento del Cesar donde se concentra el mayor número de electores y candidatos a cargos de elección popular, ha sido notorio que los partidos políticos funcionan como organizaciones burocratizadas, movilizadoras de recursos económicos para ser invertidos en las campañas electorales, facilitando el establecimiento de acuerdos con sectores de la sociedad para ser beneficiados a cambio de apoyo político, afectando la legitimidad del proceso electoral, al igual que la participación justa e imparcial de los candidatos a concejales de la región.

Asimismo, evidencian irregularidades en el financiamiento de las organizaciones políticas, hecho conducente a la intervención de instancias jurídicas para garantizar la no violación de las normas electorales y leyes establecidas. Todo esto pudiese estar ocurriendo por la presencia del clientelismo político, afectando el adecuado desenvolvimiento de la participación electoral de los candidatos aspirantes a cargos de gestión pública y provocando la inclinación de los electores bajo la coacción de un intercambio de bienes o servicios, en lugar de seleccionar el postulante según sus propios criterios, sea considerado como el mejor capacitado para satisfacer las necesidades del municipio.

De continuar esta situación, el municipio estará envuelto en hechos de manipulación electoral, captación indebida del voto, utilización de fondos del Estado de forma ilegítima, hechos de corrupción limitantes de una participación democrática, ética, genuina e igualitaria tanto para los electores, como los candidatos. De ahí, surge el interés de plantear el presente estudio con el objetivo de analizar el clientelismo político en la gestión pública resaltando sus características y consecuencias como forma de dominación política en el municipio Valledupar-Departamento del Cesar, Colombia durante el periodo 2011 a 2015, para al final aportar recomendaciones 
Antonio Yesid Pedroza Estraday Robert Romero Ramírez.

Telos Vol. 20, No. 2 (2018). 330-355

dirigidas a mejorar la problemática antes descrita.

\section{Clientelismo político en la gestión pública.}

El clientelismo, es un asunto causante de incomodidad a quienes lo abordan desde la óptica política. En ese sentido, la derecha social, lo concibe natural, dentro de una visión jerárquica patriarcal del mundo. Por el contrario, la izquierda lo combate programáticamente, pero observa, con no poco estupor, las prácticas clientelísticas le introducen por la trastienda en su propio campo, incluso el leninismo trazó la más paradójica antinomia: permanezca la centralización jerárquica hasta la sociedad esté en condiciones sociales de acceder a la igualdad plena.

En opinión de Graziano (1975) el clientelismo genera una dialéctica entre el líder y sus seguidores, mientras permita a estos últimos lograr el acceso a recursos escasos de orden económico. Empero, estos recursos no son siempre cuantificables ni inmediatos; sino por el contrario, están sometidos a la economía de la oferta y demanda, a la tensión histórica dentro de un país.

Tratándose ciertamente de uno de los fenómenos más característicos del funcionamiento y dinámica de los procesos políticos institucionales en esta última de fase de la etapa del retorno a la democracia, el clientelismo político ha sido polisémicamente definido, caracterizado, analizado y hasta sistemáticamente condenado, en el campo de las complejas producciones discursivas: desde el discurso académico hasta el mediático en sus múltiples variantes, pasando por las de los propios agentes sociales.

En este orden de ideas, Graziano (1975, p. 45) hace una importante distinción a propósito del intercambio y el clientelismo: "El intercambio social está típicamente basado en incentivos materiales, esto es no socaban el statu quo; ideológicamente, en contraste, es un valor expresivo y puede permitir la trasformación del sistema”. La primera modalidad, abarca el campo de lo racional; mientras que la segunda, lo hace en el campo de lo irracional. El primero será acomodaticio, pragmático, orientado 
Clientelismo político en la gestión pública: Características y consecuencias como forma de dominación política

hacia la conservación; el segundo, idealista, normativo, encaminado hacia la transformación.

Para Machado (2007) el clientelismo político ha sido representado, en su sentido social dominante, como un desvío, una distorsión o falla en el sistema democrático. Asignado a contextos poblacionales de grupos sociales marginados, caracterizado como un síntoma de la ajenidad y anacronismo propia de aquellos con una forma típica de actuación política donde conjuga la competencia electoral con un sistema de exclusión social extendido.

Visto así, para Auyero (2004) es entendido como un intercambio de favores por votos. Pero sobre todo, es un intercambio relacional cuyo propósito es establecer y alimentar una relación personal duradera entre las partes, surge cuando uno de los socios (candidatos, autoridades gubernamentales, líderes de partidos políticos) tiene claramente mayor posibilidad de movilizar bienes y servicios a cambio de lealtad, información y apoyo político de sectores de la sociedad para ellos poder disfrutar del poder por un período prolongado de tiempo.

El carácter político del clientelismo es indispensable para determinar el fenómeno, los diversos acontecimientos han rodeado la evolución del mismo, han estado acompañados de cambios y transformaciones al interior del sistema político, Los comportamientos del pasado son claves referentes para identificar la manera como este fenómeno ha insertado en la política pública, y en la manera como moldean las directrices estatales desde los múltiples sectores de intervención, fenómeno más evidente en unas líneas y en otras.

No obstante, la conducta clientelar, puede manifestar en algunos momentos como sutil, anclada al uso oportuno de las coyunturas y los escenarios en los cuales desplaza la acción política, mientras la corrupción la encontramos directamente en la aplicación de las políticas públicas, y sobre todo para el caso estudiado ligada al papel ineficiente de la administración pública del sector.

En ese sentido, en el clientelismo surgen negocios de posiciones políticas, facilitándose accesos, creando relaciones dirigidos a los intereses perseguidos, la 
corrupción por su parte, es un mecanismo más agresivo mediante el cual pervierte la relación social, y entre otras muchas situaciones, pueden llegar a malversarse los recursos de interés público. A veces el límite entre una y otra conducta puede ser difuso, ambas pueden manifestar en una negociación realizada donde aprovechan las múltiples ventajas y recursos, para finalmente desarrollar una actividad corrupta.

\section{Características del clientelismo político.}

De acuerdo con González (2007) el clientelismo político entre países, muchos de ellos teóricamente independientes tras el proceso de descolonización, presenta las mismas características del clientelismo tradicional: una estructura normativa, donde todos son libres e independientes, y una estructura pragmática caracterizada por la no hay libertad efectiva, los lazos con los centros de poder siguen siendo tanto o más fuertes de la época colonial. Dentro de este marco, para el citado autor, las principales características de este fenómeno son:

a. Los grupos partidarios colonizan el aparato estatal para sus maquinarias electorales continúen funcionando. Desde esta perspectiva, desarrolla un tipo especial de relación diádica en la cual los partidos políticos usan su influencia y recursos, para ofrecer beneficios a la persona de estatus más bajo, quien a su vez retribuye al patrón ofreciendo apoyo, asistencia y servicios personales.

b. Son los jefes de dichos grupos políticos quienes deciden sobre los muchos puestos burocráticos y sobre el flujo de los dineros estatales. En este caso el papel de la directiva de los partidos políticos es fundamental para el ofrecimiento de productos a los votantes (clientes), coadyuven al convencimiento de éstos para el apoyo a la mejor propuesta.

c. A los partidos políticos le yuxtaponen redes personales disputan entre sí los recursos estatales; indudablemente es importante los acercamientos realizados, los compromisos asumidos, el apoyo recibido para el logro del objetivo trazado, creándose tejidos especiales de diversos factores favorecedores de una u otra manera a 
Clientelismo político en la gestión pública: Características y consecuencias como forma de dominación política

la consecución de la meta propuesta, es un equipo de trabajo fortalecedor de las relaciones.

d. Desaparece la diferencia entre los partidos para convertirse en redes de clientelismo. Son importantes los pactos posibles de ejecutar entre las organizaciones políticas, porque al constituir un solo bloque las coaliciones logran mejores resultados en comparación con los intereses individualistas.

e. Gracias al poder de los hechos, el sistema clientelista asegura por largos periodos el suficiente apoyo de la población como para subsistir: Si hay buenas perspectivas en relación al cumplimiento de sus deseos o necesidades inmediatas, el beneficiario apoya al benefactor en las elecciones siguientes.

Además de las características propias de las relaciones clientelistas antes enumeradas, existe también diversidad en la forma concreta de asumirlas. Las diferencias, según Kaufman (1974) pueden apreciarse en dos áreas. La primera, es el lugar ocupado por las relaciones clientelistas en el contexto institucional más amplio, es decir, determinar la medida en las relaciones clientelistas representan un componente esencial o no de la matriz institucional de una sociedad, del modo de organizar intercambios, ejercer control, y articular intereses. La segunda, referida a la dimensión organizativa o formas concretas de relación clientelista.

Puede apreciarse de las postura de autores como González (2007) la existencia de un cúmulo preciado de características propias del clientelismo como herramienta para la consecución de favores políticos donde prevalece la divergencia y anomalía en relaciones de poder al mismo tiempo de brindar protección recíproca formulada en términos de identidad particular e impresiones interpersonales de compromisos.

\section{Consecuencias del clientelismo político.}

Desde un punto de vista estrictamente económico Machado (2007) señala en el clientelismo político existe en el fondo una relación de naturaleza mercantil, donde el político cede un bien al cliente para recibir de éste un favor, por tanto no constituye un verdadero estímulo para el desarrollo productivo. Por otra parte, es disfuncional al 
desarrollo de la sociedad porque por lo general, los recursos financieros para obtener los favores de la clientela proceden del erario público y deberían ser empleados en las prioridades del país, por lo de uno u otro modo, afectan el desarrollo de la sociedad.

Por otra parte, el mismo autor explica la perversidad del clientelismo en lo tocante a su afectación a las masas empobrecidas estriba especialmente, en el ciudadano afectado por la práctica clientelar, llega incluso a ver a quien la ejerce desde su poder sociopolítico y económico como a alguien le está haciendo a él un gran favor, lo ayuda con algo a paliar sus necesidades apremiantes, cuando en realidad lo está haciendo es contribuyendo expresamente a mantenerlo en su miseria. En otras palabras, participa en la relación clientelar en contra de sus más genuinos y estratégicos intereses.

Desde este punto de vista, en la relación clientelar usualmente existe un acuerdo implícito no escrito, lo cual siempre es más ventajoso para quien tiene el poder y el recurso o dinero para someter, en consecuencia puede llegar incluso a recibir el favor del ciudadano a cambio solo de una promesa con la esperanza de verla hecha realidad, ya la misma podría finalmente no llegar a cumplirse

El clientelismo, de acuerdo con González (2007) anula y desvirtúa el empoderamiento de la ciudadanía y su participación en los asuntos del país, la desestimula sistemáticamente al enajenar mediante la relación clientelar en las cúpulas políticas y económicas asociadas, su participación en las decisiones. Quienes pasan a apropiarse así del derecho ciudadano mediante las prácticas clientelares, sienten además en el derecho de ser quienes deben decidir por este, es un derecho ilegítimo, pero adquirido.

Dentro de este marco, el deber del político para con el ciudadano elector queda saldado con la protección clientelar o con la entrega de dinero u otros bienes, mientras, la parte de la sociedad fuera de la relación político-clientelar sale de la responsabilidad de la autoridad gubernamental elegida o del amparo del partido político quedando en desventajas frente a los grupos favorecidos. En consecuencia, el 
Clientelismo político en la gestión pública: Características y consecuencias como forma de dominación política

clientelismo divide a la ciudadanía, opone a unos ciudadanos a otros, privilegia sin méritos a unos sobre otros.

En esta perspectiva, Eisenstadt y Roniger (1984) plantean de manera fundamental saber separar las relaciones constructoras de lealtades, confianza mutua, reciprocidad y obligaciones de correspondencia para toda la sociedad demandante de la satisfacción de necesidades, del clientelismo político, es decir, delimitarlo de la solidaridad, saberlo separar de las políticas públicas justas no condicionadas al voto y al apoyo político como obligación de los ciudadanos. Según estos autores algunas consecuencias del clientelismo político son las siguientes:

a. Aumenta el descontrol estatal, los recursos son distribuidos con criterios particularistas. Ocurre una anarquía general en la distribución de los recursos del Estado, atiende a criterios individualistas en favor de aquel o aquellos unidos para el logro de los objetivos partidistas para beneficio de las partes.

b. Los proyectos de inversión a largo plazo son poco viables. Lamentablemente, el proceso de desarrollo presupuestario para proyectos a largo plazo, son difíciles de alcanzar porque la mayoría de las partes involucradas buscan su beneficio a corto o mediano plazo, en consecuencia es casi imposible alcanzar ventajas destinadas a largo plazo.

c. Ineficiencia del aparato estatal, esta consecuencia en la mayoría de los casos es la más resaltante porque con tantos compromisos asumidos producto de la relación patrono-cliente, es casi imposible cumplirle a todos, y en caso de alcanzarlo, esa retribución no cumple los estándares esperados por quien aspira el beneficio, en este caso es el cliente o votante.

d. Inequidades en la distribución de riquezas por parte del Estado. Resulta casi imposible para el Estado repartir de manera equitativa los recursos o prebendas ofrecidas para la obtención de lo requerido, precisamente por la diversidad de factores confluyentes en esa distribución y no permite igualdad entre todos los clientes. 
e. Escasa resolución de los problemas sociales: Indiscutiblemente, la solución a la diversidad de dificultades presentes el entorno social con el cual se efectuó la negociación de algún tipo de prebenda o beneficio, es apenas un grano de arena en el inmenso desierto constituye la realidad de las comunidades involucradas.

f. Pérdida de la línea divisoria entre lo privado y lo público. Particulares pasan a apropiarse de los bienes públicos. En algunos casos dan hechos de corrupción facilitando la expropiación o apropiación de bienes del Estado como retribución por el favor concedido.

g. Falta de promoción del debate colectivo sobre los conflictos y temas sociales, cada individuo o cada pequeño grupo fragua su propia estrategia negociadora frente al respectivo protector.

h. Fomenta la corrupción y la violencia. El clientelismo político genera hechos de corruptela y de violencia porque muchas veces busca la satisfacción de intereses individuales por encima de los colectivos o comunes.

Adicionalmente, afirman Eisenstadt y Roniger. (1984) el clientelismo político tiene otras importantes consecuencias éticas porque su práctica continuada va alejando al ciudadano de sus deberes para con la sociedad, actuando de forma indiferente a lo realizado en materia política, eso queda en manos de quienes son dueños de la clientela, alejando al ciudadano del civismo. Conduce, por tanto, a la despersonalización política del ciudadano, al sustituir su participación con criterio personal, por la voluntad de quien lo practica en provecho corporativo e individual. En consecuencia, la práctica clientelar, contribuye a un menor empoderamiento de la ciudadanía y pérdida de su personalidad política.

Aunado a esta idea, dada su esencia mercantil puede ser cada vez más costoso. Su práctica puede derivar en que las cúpulas políticas en las campañas electorales, terminen financiando no solo a su clientela, sino también la de sus propios correligionarios políticos para activar su participación en la actividad política, 
Clientelismo político en la gestión pública: Características y consecuencias como forma de dominación política

sellando con ello el fin de la militancia consciente, convencida de una ideología política, y ahora mercantilizada e ideológicamente desvalorizada.

\section{Metodología.}

Basado en Bracker (2002) la investigación enmarcó en el paradigma cualitativo, adoptando el método hermenéutico-interpretativo. Según Cárcamo (2005) a través de la hermenéutica, el investigador procura comprender los textos a partir del ejercicio interpretativo intencional y contextual. Dicho proceso, supone desarrollar la inteligibilidad del discurso contenido en el texto; en gran medida trata de traspasar las fronteras contenidas en la física de la palabra para lograr la captación del sentido de éstas en tanto plasmadas en un papel.

Además de acuerdo con Arias (2012) y Sabino (2006) fue de tipo documental y de diseño bibliográfico; soportando el estudio en textos, leyes y artículos científicos, seleccionados de forma intencional siguiendo como criterios estar relacionados en contenido con la categoría de análisis resultando de esta forma, la recopilación de 17 documentos para facilitar la comprensión, reflexión e interpretación del clientelismo político en la gestión pública municipal en los procesos de elección popular de los candidatos de partidos políticos pretenden ocupar una curul en corporaciones administrativas, como es el caso del concejo municipal de Valledupar Departamento del Cesar, Colombia durante el período 2011 a 2015.

Dentro de este enfoque metodológico, fue aplicado el modelo de análisis hermenéutico propuesto por Baeza (2002) donde: A: hace referencia al contexto del otro (autor teórico), B: hace referencia al contexto propio (contexto investigado), C: refiere a la interpretación considerada como propuesta apoyada en la síntesis realizada previamente (investigador). 
Figura 1. Modelo de análisis hermenéutico

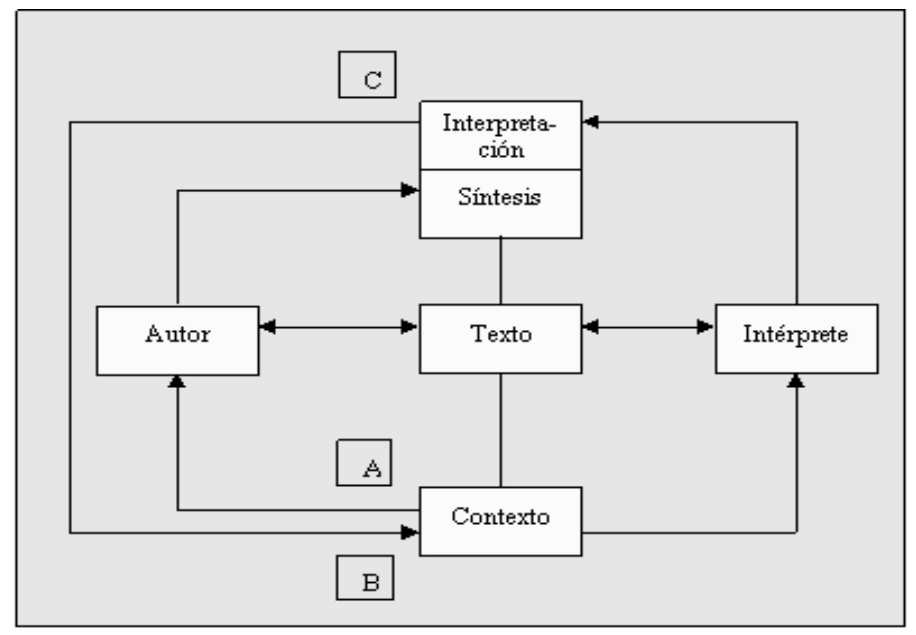

Fuente: Baeza (2002)

El modelo presentado, representa un proceso facilitador para el desarrollo de la praxis hermenéutica; por cuanto reconoce y explicita los principales aspectos a considerar para ser llevado de manera apropiada.

\section{Resultados.}

En el cuadro 1, son incluidos los resultados correspondientes a las características del clientelismo político en la gestión pública municipal de ValleduparCesar durante el periodo 2011 a 2015:

Cuadro 1. Síntesis de los resultados del análisis hermenéutico de Características del clientelismo político

\begin{tabular}{|l|l|l|}
\hline A (Contexto del otro) & $\boldsymbol{B}$ (Contexto propio) & \multicolumn{1}{c|}{$\begin{array}{c}\text { (Interpretación como } \\
\text { propuesta) }\end{array}$} \\
\hline $\begin{array}{l}\text { Colonizan el aparato } \\
\text { estatal }\end{array}$ & $\begin{array}{l}\text { Las relaciones patrón/ cliente } \\
\text { indiscutiblemente presentan la } \\
\text { característica primordial de } \\
\text { colonizar al Estado, porque va } \\
\text { a haber un dependencia }\end{array}$ & $\begin{array}{l}\text { Debe realizarse una propuesta } \\
\text { de gestiones públicas } \\
\text { transparentes y la rendición de } \\
\text { cuentas. }\end{array}$ \\
\hline
\end{tabular}




\begin{tabular}{|c|c|c|}
\hline & mutua & \\
\hline $\begin{array}{l}\text { Son los jefes de los } \\
\text { quienes deciden sobre } \\
\text { los puestos burocráticos } \\
\text { y sobre el flujo de los } \\
\text { dineros estatales }\end{array}$ & $\begin{array}{l}\text { Quienes detentan el poder } \\
\text { pueden disponer de los cargos } \\
\text { y de la distribución de los } \\
\text { recursos en el Municipio } \\
\text { Se origina el amiguismo yla } \\
\text { filiación en la gestión pública }\end{array}$ & $\begin{array}{l}\text { Debe trabajarse en función de } \\
\text { proyectos reales con un } \\
\text { adecuado uso de los recursos } \\
\text { económicos y la evaluación de } \\
\text { credenciales para asumir los } \\
\text { cargos }\end{array}$ \\
\hline $\begin{array}{l}\text { La relación ocurre entre } \\
\text { actores de poder y } \\
\text { estatus desigual }\end{array}$ & $\begin{array}{l}\text { Se establece la relación entre } \\
\text { quienes hacen el ofrecimiento } \\
\text { con aquellos cuyas } \\
\text { necesidades requieren ser } \\
\text { cubiertas en Valledupar. } \\
\text { Expresan el poderío de } \\
\text { quiénes tienen los recursos } \\
\text { sobre los necesitados }\end{array}$ & $\begin{array}{l}\text { Buscar un equilibrio en la } \\
\text { relación clientelar, mejorar el } \\
\text { bienestar social, proyectando } \\
\text { acciones inclusivas y de } \\
\text { respeto a los ciudadanos }\end{array}$ \\
\hline $\begin{array}{l}\text { Intercambio simultáneo } \\
\text { de recursos de } \\
\text { diferentes tipos, sobre } \\
\text { todo, económicos y } \\
\text { políticos }\end{array}$ & $\begin{array}{l}\text { Son otorgados } r \text { favores } \\
\text { económicos o políticos, } \\
\text { básicamente de } r \text { tipo } \\
\text { mercantilista para el apoyo a } \\
\text { un candidato en Valledupar }\end{array}$ & $\begin{array}{l}\text { Los recursos disponibles en } \\
\text { los entes gubernamentales } \\
\text { deben ser objeto de control } \\
\text { social }\end{array}$ \\
\hline $\begin{array}{l}\text { Es expresado } \\
\text { usualmente en términos } \\
\text { de lealtad }\end{array}$ & $\begin{array}{l}\text { La persona beneficiada } \\
\text { establece un compromiso de } \\
\text { lealtad hacia su benefactor. }\end{array}$ & $\begin{array}{l}\text { Sacar provecho a esos } \\
\text { sentimientos de lealtad }\end{array}$ \\
\hline $\begin{array}{l}\text { Las relaciones entre } \\
\text { patronos y clientes no } \\
\text { son fundamentalmente } \\
\text { legales o contractuales }\end{array}$ & $\begin{array}{l}\text { En Valledupar las relaciones } \\
\text { patrón/cliente son más de tipo } \\
\text { interpersonales o de beneficio } \\
\text { mutuo }\end{array}$ & $\begin{array}{l}\text { Elaboración de contratos de } \\
\text { servicios donde sean } \\
\text { involucradas ambas partes }\end{array}$ \\
\hline $\begin{array}{lr}\text { Las } & \text { relaciones } \\
\text { clientelistas } & \text { son } \\
\text { asumidas en forma } \\
\text { vertical en términos de } \\
\text { lealtad }\end{array}$ & $\begin{array}{l}\text { Las relaciones entre los } \\
\text { candidatos a las curules en } \\
\text { Valledupar y los ciudadanos, } \\
\text { son establecidas de manera } \\
\text { jerarquizada y con lealtad al } \\
\text { favor concedido }\end{array}$ & $\begin{array}{l}\text { Es recomendable el uso de un } \\
\text { modelo horizontal y/o cíclico, } \\
\text { partiendo de una nueva } \\
\text { gerencia pública. }\end{array}$ \\
\hline
\end{tabular}

Fuente: Elaboración propia

Partiendo de la triangulación presentada en el cuadro 1, puede expresarse que para autores como González (2007), Kaufman (1974), Eisenstadt y Roniger (1984), identificados como (A), existen características propias del clientelismo político, como son la colonización del aparato estatal, los puestos burocráticos y el flujo de los dineros estatales, es una decisión de los jefes, los partidos pasan a convertirse en redes de clientelismo, asegurando por largos periodos el suficiente apoyo de la población, 
esta relación ocurre entre actores con poder y estatus desigual, pero basado en el principio de la reciprocidad, siendo a la vez particularista y privada.

De igual forma, es establecido un intercambio simultáneo de recursos de diferentes tipos, expresamente económico y político, manifestándose dicha relación en términos de lealtad. Asimismo, las relaciones entre patronos y clientes no son fundamentalmente legales o contractuales aunque inician de manera voluntaria, son asumidas en forma vertical, finalmente, caracterizado porque las relaciones son muy desiguales y expresan la diferencia de poder entre unos y otros.

En función de estas características, desde el punto de vista del contexto de la presente investigación (B), en el municipio de Valledupar Departamento del Cesar el clientelismo político es visualizado categóricamente porque las relaciones patrón/cliente (ciudadano) indiscutiblemente presentan la característica primordial de colonizar al Estado, porque va a haber una dependencia mutua, aunque precisamente quienes detentan el poder, disponen de los cargos y distribución de los recursos en el Municipio, en este caso los Alcaldes, originándose el amiguismo y la filiación en la gestión pública, precisamente por los favores debidos.

En este orden de ideas, mientras ocurra una relación mutua de comprensión y apoyo, indiscutiblemente las mismas pueden perdurar durante largos períodos, pero para ello, precisamente requiere la existencia entre quienes detentan el poder (por lo cual hacen el ofrecimiento) y los desposeídos (tienen necesidades a cubrir), relaciones muy particulares.

En efecto, en el clientelismo político en Colombia para el período 2011-2015, fueron otorgados favores casi siempre económicos o políticos, bien para el apoyo de un candidato o partido político con el interés de ganar o asegurarse una curul y el cliente o ciudadano quien busca en su representante, ayuda en la solución de los problemas comunitarios, básicamente sucede un intercambio, desde el punto de vista mercantilista. Empero, es relevante para la persona receptora de un beneficio para el sector o municipio donde habita, sentirse en correspondencia con un compromiso de 
Clientelismo político en la gestión pública: Características y consecuencias como forma de dominación política

lealtad hacia su benefactor. Del mismo modo, también el alcalde o concejal, debe dar muestras de lealtad hacia ese ciudadano otorgante del apoyo (voto) concedido.

Dentro del contexto de estudio, las relaciones patrón/cliente no están sustentadas por escrito en ninguna ley o contrato, porque trata más de relaciones interpersonales de beneficio mutuo. En principio dentro de la comunidad de Valledupar, en el Cesar, estas relaciones interpersonales son voluntarias, es decir, no existe coacción, ni presión alguna para forzar el desarrollo de las mismas, sino por el contrario surge la empatía entre el ciudadano y su candidato, y esta puede perdurar en el tiempo, siempre y cuando el beneficio mutuo permanezca.

Entre los candidatos a las curules en Valledupar y los ciudadanos, dan las relaciones de manera jerarquizada o vertical, porque quien detenta el poder, necesita de su cliente, debido a la disponibilidad de los recursos económicos y políticos para mantenerlo sujeto a él. Como ha sido descrito hasta ahora, para el período 2011-2015, estas relaciones patrón/cliente, son muy particulares porque expresan el poderío de quien tiene los recursos sobre el desposeído, quien al no unirse al candidato disminuye la posibilidad de obtener la satisfacción de sus necesidades.

Ahora bien, tomando en consideración las propuestas dadas a partir de la síntesis hecha e identificadas como (C), debe realizarse una propuesta coadyuvante a la descolonización del Estado, a través de gestiones públicas transparentes y la rendición de cuentas. De tal modo, la relación no debe establecerse solamente por el amiguismo o la familiaridad, sino a través de un trabajo en equipo para el logro de la satisfacción de las necesidades en función de proyectos planteados para el buen uso de los recursos económicos y la evaluación de credenciales para asumir los cargos de elección popular.

Asimismo, en lugar de redes de clientelismo, debe procurarse el surgimiento de redes de conocimiento, facilitando la interacción patrón/cliente por medio equipos con cuyo trabajo logren compartir no solo roles sino también, sus sapiencias en el logro de las metas sociales. Por medio del clientelismo, puede aprovechar los aspectos 
positivos de éste para reforzar la colaboración mutua, dejando de lado intereses personales.

Visto de esta forma, debe buscarse un equilibrio entre ambos extremos de la relación clientelar, haciendo prevalecer una sintonía entre los recursos disponibles con los objetivos a lograr. Desde esta perspectiva, la reciprocidad presente en la relación patrón/cliente, debe ayudar a mejorar el bienestar social, los rastros de desigualdad y exclusión presentes en Valledupar.

En este contexto, sería prudente sugerir la elaboración de contratos de servicios donde sean involucradas a ambas partes (Municipio como prestador del mismo y el ciudadano como usuario), de esta forma si el cumplimiento de las funciones no ocurre de manera voluntaria, el ciudadano pueda exigir el cumplimiento del contrato so pena de resarcimiento, de esta manera los representantes estaría más prestos al cumplimiento y el ciudadano a defender sus derechos, pero cumpliendo a la vez con sus obligaciones.

Aun cuando la mayoría de las relaciones parón/cliente ocurren de forma jerárquica, es decir vertical, sería prudente el uso de un modelo horizontal y/o cíclico, partiendo de una nueva gerencia pública caracterizada por saber escuchar y saber disponer de los recursos para el bienestar general. Por ende, los recursos disponibles en los entes gubernamentales deben ser objeto de control social por parte de los organismos encargados, de tal. En este caso, sería favorecedor para ambas partes, mantener relaciones igualitarias, sin muestras de ningún tipo de dominio por parte de quien posee y genera los recursos, sino por el contrario, al crearse relaciones de este tipo el ciudadano siente una mejor representación.

En cuanto a las consecuencias del clientelismo político en la gestión pública municipal de Valledupar en el Cesar durante el periodo 2011 a 2015, son presentados en el cuadro 2, los siguientes resultados. 


\section{Cuadro 2. Síntesis de los resultados del análisis hermenéutico de Consecuencias del clientelismo político}

\begin{tabular}{|c|c|c|}
\hline$A$ (Contexto del otro) & B (Contexto propio) & $\begin{array}{c}C \text { (Interpretación como } \\
\text { propuesta) }\end{array}$ \\
\hline $\begin{array}{l}\text { Disfuncional al desarrollo } \\
\text { de la sociedad. Desvirtúa } \\
\text { el empoderamiento de la } \\
\text { ciudadanía }\end{array}$ & $\begin{array}{l}\text { La ciudadanía no logra } \\
\text { empoderarse para participar } \\
\text { activamente en la gestión }\end{array}$ & $\begin{array}{l}\text { Proyectar la inclusión de los } \\
\text { ciudadanos a través de la } \\
\text { participación ciudadana }\end{array}$ \\
\hline $\begin{array}{l}\text { Su práctica continuada y } \\
\text { sistemática va alejando al } \\
\text { ciudadano de sus deberes } \\
\text { cívicos o con la sociedad. }\end{array}$ & $\begin{array}{l}\text { Los ciudadanos sienten estar } \\
\text { relegados y por ende, } \\
\text { desmotivados a participar en } \\
\text { la gestión pública municipal }\end{array}$ & $\begin{array}{l}\text { Proponer mesas de trabajo } \\
\text { en los sectores vulnerables } \\
\text { de Valledupar para } \\
\text { contribuir con la solución de } \\
\text { los problemas del municipio. }\end{array}$ \\
\hline $\begin{array}{l}\text { Hay una espiral perversa } \\
\text { reproductora del } \\
\text { clientelismo asociada a la } \\
\text { pobreza, autoritarismo, } \\
\text { ignorancia, corrupción y } \\
\text { otros males sociales }\end{array}$ & $\begin{array}{l}\text { Algunas prácticas bien } \\
\text { partidistas o de algún } \\
\text { candidato conducen a actos de } \\
\text { corrupción }\end{array}$ & $\begin{array}{lr}\begin{array}{l}\text { Crear } \\
\text { comunitarios }\end{array} & \begin{array}{r}\text { proyectos } \\
\text { donde }\end{array} \\
\text { participen los entusiastas } \\
\text { pero también a los apáticos, } \\
\text { demostrando la búsqueda del } \\
\text { beneficio colectivo y no para } \\
\text { una sola persona }\end{array}$ \\
\hline $\begin{array}{l}\text { Aumenta el descontrol } \\
\text { estatal. Los recursos son } \\
\text { distribuidos con criterios } \\
\text { particularistas. }\end{array}$ & $\begin{array}{l}\text { Es observada anarquía en el } \\
\text { ejercicio de la gestión pública } \\
\text { porque los recursos no son } \\
\text { distribuidos de manera } \\
\text { equitativa }\end{array}$ & $\begin{array}{l}\text { Hacer asambleas de calle o } \\
\text { de ciudadanos para generar } \\
\text { proyectos sociopolíticos } \\
\text { capaces de obtener recursos } \\
\text { económicos para su } \\
\text { desarrollo. }\end{array}$ \\
\hline $\begin{array}{l}\text { Los proyectos de inversión } \\
\text { a largo plazo son } \\
\text { prácticamente imposibles } \\
\text { de ejecutar. }\end{array}$ & $\begin{array}{l}\text { Búsqueda de beneficios } \\
\text { efectivos a corto o quizá } \\
\text { mediano plazo para sí mismo } \\
\text { o para su colectividad }\end{array}$ & $\begin{array}{l}\text { Planificar proyectos a corto } \\
\text { y mediano plazo para la } \\
\text { satisfacción de necesidades a } \\
\text { través de la gestión pública, }\end{array}$ \\
\hline $\begin{array}{l}\text { Ineficiencia del aparato } \\
\text { estatal. }\end{array}$ & $\begin{array}{l}\text { Los ciudadanos presentan sus } \\
\text { inconformidades con la } \\
\text { gestión pública de sus } \\
\text { representantes municipales }\end{array}$ & $\begin{array}{l}\text { Establecer redes para ejercer } \\
\text { un control social en la } \\
\text { gestión pública }\end{array}$ \\
\hline $\begin{array}{l}\text { Escasa resolución de los } \\
\text { problemas sociales: Estos } \\
\text { son mitigados } \\
\text { provisionalmente }\end{array}$ & $\begin{array}{l}\text { Problemas } \\
\text { presentados a diario, con } \\
\text { escasa atención por los entes } \\
\text { públicos. }\end{array}$ & $\begin{array}{l}\text { Establecer equipos de } \\
\text { trabajo o comisiones con la } \\
\text { capacidad de atender } \\
\text { necesidades concretas }\end{array}$ \\
\hline
\end{tabular}

Fuente: Elaboración propia

Siguiendo con la triangulación en el cuadro 2, para (A), autores como Machado (2007), González (2007) y Eisenstadt y Roniger(1984), la existencia de consecuencias del clientelismo político, tales como: Es disfuncional al desarrollo de la sociedad 
porque por lo general los recursos financieros para obtener los favores de la clientela proceden del erario público cuando deberían ser empleados en las prioridades del país.

También anula y desvirtúa el empoderamiento de la ciudadanía en su participación en los asuntos del país, la desestimula sistemáticamente al enajenar mediante la relación clientelar en los patronos, en las cúpulas políticas y económicas asociadas, su participación en las decisiones. Además tiene consecuencias éticas porque su práctica continuada va alejando al ciudadano de sus deberes para con la sociedad, éste pierde el sentido de responsabilidad sobre lo realizado en la política, eso queda en manos de quienes son dueños de la clientela.

En ese sentido, el clientelismo aleja al ciudadano del civismo, conduciéndolo a su despersonalización política, al sustituir su voluntad política, su derecho participativo, su criterio personal, por la voluntad de quien lo practica en provecho corporativo e individual. De igual forma, al mercantilizar la política y hacerla por cauces espurios, obstaculiza y llega a suprimir el libre intercambio de ideas, las iniciativas políticas y los deseos de cambio, vaciando el ejercicio de la política de contenido ideológico y ético.

Puede inferirse según los autores analizados, la presencia de una espiral perversa favorecedora de la reproducción del clientelismo asociada a la pobreza, al autoritarismo, a la ignorancia, a la corrupción y otros males sociales. Además, aumenta el descontrol estatal, los recursos son distribuidos con criterios particularistas. Es decir, atiende a criterios individualista en favor de los contribuyentes al logro de los objetivos trazados, esto es producto de la interacción llevada a cabo para beneficio de las partes.

De igual forma, otra consecuencia relacionada con los proyectos de inversión a largo plazo, es precisamente la dificultad para ser ejecutados por falta de asignación de recursos desviados a mantener la relación clientelar, contribuyendo a la ineficiencia del aparato estatal, porque con tantos compromisos asumidos en la relación patronocliente, es casi imposible cumplirles a todos. También trae inequidades en la 
Clientelismo político en la gestión pública: Características y consecuencias como forma de dominación política

distribución de riquezas por parte del Estado, ocurriendo una escasa solución radical de los problemas sociales, siendo mitigados provisionalmente.

Ahora bien en relación con estas consecuencias, desde el punto de vista de los autores de la presente investigación (B), en el municipio de Valledupar Departamento del Cesar, para el período 2011-2015, el dinero del Erario Público, en algunos casos fue empleado también en beneficio de aquellos ciudadanos otorgantes del apoyo solicitado a cambio de la obtención de prebendas político-económicas. Por tanto, es notorio en la ciudadanía un limitado empoderamiento para participar activamente en la gestión pública, porque las relaciones clientelares prevalecen ante las necesidades sociales.

Precisamente en Valledupar la mayoría de los ciudadanos perciben estar relegados y por ende, desmotivados a participar en la gestión pública municipal, debido a la mayoría de las relaciones suceden entre patrono/cliente, dejando a un lado los intereses colectivos, por ende no muestran ningún tipo de interés políticamente hablando, por lo ocurrido en su entorno.

Lamentablemente, en cierta medida en el municipio de Valledupar algunas prácticas partidistas o de algún candidato, han terminado en actos de corrupción, siendo esto causa de desinterés y hasta falta de conciencia en los ciudadanos por sentirse defraudados por el sistema, expresando en algunos casos su inconformidad con el régimen democrático.

De acuerdo con el análisis efectuado, en la sociedad de Valledupar, como en muchas de América Latina, es observada la anarquía en el ejercicio de la gestión pública porque los recursos no son distribuidos de manera equitativa sino por el contrario, prevalece compensar el favor concedido. Por ende, el sector otorgante de mayor apoyo al candidato por las prebendas ofrecidas, va a obtener mayores beneficios en comparación con quienes no lo hagan.

Dentro de este marco, cuando el ciudadano en Valledupar busca beneficios para sí mismo o para su colectividad, indudablemente desea sean efectivos a corto o 
quizá a mediano plazo, pero nunca quiere a largo plazo porque las situaciones sociopolíticas en el Municipio son cambiantes, por ello quizá no pueda disfrutar los mismos.

En este contexto, una de las mayores quejas de los ciudadanos del municipio de Valledupar de acuerdo con entrevistas informales, es precisamente la distribución de los recursos de forma desigual, es decir, tomando en cuenta los señalado por los autores y el conocimiento experiencial en esta investigación, son diversos los factores influyentes en la distribución por parte del ente municipal, pero ejerciendo mayor peso el clientelismo político

Desde esta perspectiva, en el municipio objeto de estudio, ocurren a diario problema sociales no siendo adecuadamente atendidos por los entes en su gestión pública, casi siempre la solución es momentánea para algunas situaciones, pero estudiando a fondo las dificultades. Esta situación sucede en forma cálcica, es cubierta una etapa de supuesta solución, surgiendo más adelante el mismo problema pero más profundo y subsumido en mayores necesidades sociales de los ciudadanos, visto así prácticamente es en un asunto inagotable para la gestión pública de Valledupar.

Por otra parte, en ocasiones el clientelismo político ha conllevado a hechos violentos y actos de corrupción en el municipio, porque son varios los actores involucrados, presentándose estos hechos inapropiados porque cada cual busca la satisfacción de intereses personalistas.

Ahora bien, tomando en consideración las propuestas dadas (C), es necesario proyectar una nueva forma de gerencia pública planteada para minimice la disfunción social a causa del clientelismo político, creando al mismo tiempo, entornos favorables al desarrollo del municipio Valledupar y por ende, evitar gastos extravagantes en el Erario Público sin debida justificación.

De ahí sería bueno, proyectar a través del nuevo modelo de gestión, la inclusión de los ciudadanos a través de la participación ciudadana protagónica en la construcción de sus problemas públicos, entendido este como un constructo político. Tal como lo plantean Pedroza y Colina (2016) los representantes de la sociedad 
Clientelismo político en la gestión pública: Características y consecuencias como forma de dominación política

pueden llevar los problemas colectivos a la agenda pública para la búsqueda de soluciones satisfactoria para toda la comunidad diseñando políticas públicas acordes. Por ende, deben proponer mesas de trabajo en los sectores vulnerables de Valledupar para la búsqueda en conjunto de solución a los problemas públicos aportando calidad de vida a la comunidad del municipio. De de esta manera, el ciudadano pasa a ser incluido y genera sentido de pertenencia, llevándolo a preocuparse más por el bienestar común por encima del particular.

En este caso, es recomendable crear conciencia en los ciudadanos, para promover en ellos subsumirse en las dificultades presentes en la comunidad y aportar ideas e iniciativas propias para aportar solución a las dificultades de las cuales no está exento. Es importante también, crear proyectos comunitarios con la participación de los entusiastas pero también de los apáticos, demostrando el alcance del beneficio colectivo, dejando de lado actividades clientelares en menosprecio de la mayoría de los desasistidos, excluidos o no tomados en cuenta, quienes bajo esta condición expresan decepción de la actividad sociopolítica y por ello, muchas veces no participa n siquiera en procesos eleccionarios aumentando en este caso la abstención electoral.

De igual forma, hacer Asambleas de calle o de ciudadanos para generar en forma consensuada, proyectos sociopolíticos capaces de obtener recursos económicos para su desarrollo y por ende, trasladar el beneficio perseguido a toda la colectividad y no para un grupo particular. También planificar proyectos a corto y mediano plazo para la satisfacción de necesidades a través de la gestión pública, utilizando de ser posible los aspectos positivos del clientelismo pero a favor de toda la comunidad y no solamente a la persona o pequeños grupos con los recursos necesarios para brindar su apoyo a un candidato o partido político

Igualmente, es necesario establecer redes para ejercer un control social en la gestión pública transformando mediante esta acción, los niveles de ineficiencia en calidad de los servicios prestados a la comunidad. Asimismo, es requerido planificar acciones para proceder a una distribución equitativa de las riquezas en el municipio, 
partiendo de las ideas aportadas por el ciudadano común en asambleas de ciudadanos y/o en mesas de trabajo, haciéndole seguimiento a las mismas.

Por otra parte, es importante establecer equipos de trabajo o comisiones para atender a necesidades concretas, atacar el origen de las mismas y no dejar campo a la improvisación ni a soluciones temporales a la situación planteada, manteniendo en latencia el problema no resuelto a fondo, en tal sentido de no dar solución a un problema originando otro. Dentro de la gestión pública, es determinante evitar los desplazamientos forzados por causa del desalojo de las tierras o en todo caso el aprovechamiento de espacios pertenecientes a la municipalidad por parte de personas favorecidas por haber brindado su apoyo al candidato, para así sacar beneficio personal de dichos espacios.

\section{Consideraciones Finales.}

En referencia a las características del clientelismo político en la gestión pública municipal de Valledupar departamento del Cesar, Colombia, la investigación permite establecer los rasgos más importantes de este fenómeno, siendo éstos la colonización del aparato estatal, la asignación de puestos burocráticos y el flujo de dineros estatales. Los partidos participan en redes de clientelismo, asegurando por largos periodos el suficiente apoyo de la población, esta relación ocurre entre actores con poder y estatus desigual, siendo a la vez particularista, recíproca y privada.

Con respecto a las consecuencias del clientelismo político en la gestión pública municipal de Valledupar en el Cesar durante el periodo 2011 a 2015, básicamente las mismas son negativas porque por lo general los recursos financieros para obtener los favores de la clientela proceden del erario público cuando deberían ser empleados en las prioridades del país. De igual manera, desvirtúa el empoderamiento de la ciudadanía en los asuntos del país al desestimular sistemáticamente la participación activa mediante la relación clientelar en los patronos.

Por otra parte, el clientelismo es implementado como forma de dominación política de las instituciones de la sociedad civil por los favores concedidos. También, 
Clientelismo político en la gestión pública: Características y consecuencias como forma de dominación política

actúa como un elemento corruptor de la vida civil, al generar de una u otra forma, dominación en los ciudadanos desde el punto de vista económico, político y social. No obstante, una vez suscitadas las relaciones clientelares en el municipio, éste puede constituirse en un elemento de corruptela en la sociedad muchas veces difícil de desinstalar porque va creando una especie de dependencia con los beneficios obtenidos.

En el municipio objeto de estudio, como en todas las sociedades dominadas por el clientelismo político, la disposición de los cargos está supeditada a las relaciones clientelares, es decir, la persona apropiada de los recursos los ofrece discrecionalmente el beneficiario para crear una situación de dependencia porque sólo así es capaz de garantizar su permanencia en el poder.

En forma general, el clientelismo político ha permeado el sistema político colombiano a nivel municipal, estableciendo relaciones jerárquicas desiguales, brindando la promoción de votos a cambio de protección, dispensa de favores o asignación de recursos públicos. Asimismo, anula y desvirtúa el empoderamiento de la ciudadanía y su participación en los asuntos del país, empero esto puede ser revertido con la aplicación de una nueva gestión pública caracterizada por la transparencia y rendición de cuentas.

\section{Referencias Bibliográficas}

Asamblea Nacional Constituyente. (1991) Constitución Política de Colombia. Extraído de: http://es.presidencia.gov.co/normativa/normativa/ConstitucionPolitica-Colombia-1991.pdfConsulta: 21/04/2016

Arias, Fridas (2012). El proyecto de investigación.(Quinta edición). Editorial Episteme. Venezuela

Audelo, Jorge (2004) ¿Qué es el clientelismo? Algunas claves para comprender la política en los países en vías de consolidación democrática. Revista Estudios Sociales. Volumen 12, núm. 24. México (Pp. 124-142).

Auyero, Javier (2004) Clientelismo político. Las caras ocultas. Ediciones Manantial. Buenos Aires, Argentina.

Baeza, Manuel (2002). De las metodologías cualitativas en investigación científico social. Diseño y uso de instrumentos en la producción de sentido. Editorial de la Universidad de Concepción. Chile 
Braker, Marem (2002) Metodología de la investigación social cualitativa.(Tercera edición). Editorial de la Universidad Politécnica de Nicaragua. Nicaragua. Extraído http://www.qualitativeforschung.de/information/publikation/modelle/bracker/metodolo.pdfConsulta $15 / 09 / 2016$

Cárcamo, Héctor (2005). Hermenéutica y Análisis Cualitativo.Cinta de Moebio. Revista de Epistemología de Ciencias Sociales, Volumen (23).Universidad de Chile. (Pp. 204-216) Extraído de: https://auroradechile.uchile.cl/index.php/CDM/article/view/26081/27386C onsulta: $14 / 05 / 2016$

Corzo, Susan (2006) El clientelismo político como intercambio. Revista Ecuador Debate.Volumen 69, núm., 2. Quito, Ecuador (Pp.103-148). Extraído de http://repositorio.flacsoandes.edu.ec/bitstream/10469/3839/1/RFLACSOED69-07-Corzo.pdfConsulta: 22/05/2016

Eisenstadt Steward y Roniger, Louis. (1984), Patrons, Clients and Friends: Impersonal Relations and the Structure of Trust in Society. Editorial de la Universidad de Cambridge. Estados Unidos de Norteamérica.

González, José Antonio (2007) El clientelismo político. Perspectiva socio antropológica. Editorial Anthropos. España.

Graziano, Luigi (1975) A conceptual frameworkforthestudyclientelism. Editorial de la Universidad de Cornell. Estados Unidos de Norteamérica.

Kaufman, Robert (1974). The Patron-Client Concept and Macro Politics: Prospects and Problems. Revista Estudios comparativos en Sociedad e Historia. Vol.16, No.4. Londres. (Pp. 284-308)

Kitschelt, Herbert. (2007) Linkages Between Citizens and Politicians in Democratic Politics. Revista ComparativePoliticalStudies. Vol. 33, núm. 6/7. Estados Unidos de Norteamérica. (Pp. 845-879) Extraído de: https://doi.org/10.1177/001041400003300607Consulta 05/08/2016

Machado, Horacio (2007) Economía política del clientelismo. Democracia y capitalismo en los márgenes. (Primera edición). Editorial Encuentro Grupo Editor. Argentina

Pedroza, Antonio, y Colina, Doris. (2016). Construcción social de problemas públicos. Editorial Inver-E-Group. Venezuela.

Sabino, Carlos (2006). El Proceso de Investigación. Editorial Panapo. Venezuela Valenzuela, Arturo (1977). PoliticalBrokers in Chile. Editorial de la Universidad de Duke. Estados Unidos de Norteamérica. 